\title{
Disruptive innovation and energy transitions: is Christensen's theory helpful?
}

Will McDowall

UCL

\section{Introduction}

Clayton Christensen's term, 'disruptive innovation', has become widespread since he introduced his theory of 'disruptive technology' in 1995 (Bower and Christensen 1995). Christensen's notion of disruptive innovation is alluring: it seems to promise that there are hidden opportunities, waiting to be stumbled upon, that can result in rapid and radical de-stabilisation of incumbent technologies. For a world desperately in need of a transformative shift towards low-carbon energy systems, what could be more promising?

Unfortunately, Christensen's idea relies on too narrow a conception of disruption and innovation to be a central framework for thinking about low-carbon transitions. It is better understood as describing one specific mechanism of technological and industrial change that contributes to a broader framework for understanding transitions. It should also be understood as a warning and reminder: businesses and policy analysts alike are prone to overlook potential shifts in user demands, and the technological changes that chase and enable them.

In this short perspective, I first set out the basic elements of Christensen's idea, making clear what is meant by 'disruptive innovation' in this context. I then examine the key shortcomings of Christensen's theory from the perspective of low-carbon transitions, before going on to show how it can still be useful.

\section{The core of Christensen's approach}

To his obvious irritation, Christensen's phrase is often used in the literature to refer to any radical or far-reaching technological change. He has argued fiercely that this devalues the original theoretical contribution, by obscuring the particular mechanisms he sought to highlight (Christensen et al. 2015). Following his argument, this article focus on Christensen's original conceptualisation of the 'disruptive innovation' idea.

Christensen's original idea was built around an overlooked and 'overserved' set of users. Lead users, he argued, are willing and able to pay more and they are demanding of high quality. Such users 
strongly influence the innovation priorities of incumbent firms. The most successful firms are those that listen closely to those users and meet their needs most effectively. But innovating firms' close relationship with these lead users is, counter-intuitively, precisely the thing that makes them vulnerable to disruption.

Leading firms, Christensen argued, overlook the fact that the product improvements they deliver aren't really needed by an increasing share of users. Such low-end users would be happy with a cheaper, simpler alternative. This creates a space for 'low-end footholds', in which lower-quality alternatives undercut incumbents, producing lower-margin (and hence lower profit) alternatives to mainstream goods and services. The low margins mean that these competing options are of little interest to incumbents, but technological learning within the low-market foothold can lead to the disruptive entrant becoming dominant.

In 2003, Christensen extended the original idea to encompass 'new market' footholds, i.e. innovations that capture markets that previous did not exist (Christensen and Raynor 2003). These 'new market' footholds serve users who were previously not just under-served, but not served at all. The tendency of radical new technologies to disrupt existing markets is of course well-trodden theoretical territory, with Schumpeter's notion of 'creative destruction' an obvious precursor - and one might object that Christensen's 'new market footholds' is old wine in new bottles. However, the contribution of Christensen's analysis here is to focus strategic and analytic attention on users that are currently not served by existing products and services.

\section{Three shortcomings of Christensen's Disruptive Innovation theory in the context of low low-carbon transitions}

As a wide range of scholars have argued (Unruh 2000; Geels 2002; Grubler 2012), low-carbon transitions require radical change across networked sets of actors, clusters of related technology, regulatory and other institutions, and user practices. Understanding and analysing such transitions requires theoretical frameworks that can encompass this broad range of concerns. I argue that Christensen's theory does not meet this need. This is perhaps unsurprising - it was never intended to be a comprehensive analytic perspective for thinking about low-carbon transitions. But in understanding how and whether it can be useful for thinking about transitions, it is helpful to first explore the reasons that disruptive innovation in Christensen's sense falls short of providing a broad framework that can account for the dynamics of low-carbon transitions. In the following, I set out three ways in which Christensen's theory is limited in its ability to account for low-carbon transitions.

\subsection{What is disrupted? Scales of disruption and continuity}

The focus of Christensen's work is the business models and innovations of firms adopting 'sustaining' and 'disruptive' strategies, the corresponding industry dynamics, and the implications for strategic managers in firms. His perspective simply excludes wider systemic interactions and concerns. Yet for a low-carbon transition, disruption to a particular set of incumbent firms and specific technologies may have little relevance to the wider high-carbon socio-technical system, as the two examples below illustrate. 
Christensen's historical accounts of the disruptions brought by Japanese manufacturers to the motorbike market shows profound re-ordering of the competitive landscape for motorbike makers. The story provides a clear example of a new market entrant exploiting a low-end foothold, and subsequently moving up-market and displacing incumbents, thus transforming the market. Yet this process had little relevance for the role of motorbikes within road transportation as a whole. This case makes clear that disruption for incumbents can be compatible with continuity for the wider socio-technical system.

In contrast, since the 1970s wind power companies adopted what Christensen would term a 'sustaining' rather than 'disruptive' strategy, competing directly with incumbents to generate gridconnected power. Their emergence has relied principally on policy support over many decades and in many countries (McDowall et al. 2013), rather than the successful exploitation of either new markets or under-served users. Yet, while they do not meet Christensen's definition of 'disruptive', these technologies have had profoundly destabilising impacts on power markets (The Economist 2017), and are at the heart of an ongoing transition to renewable energy. Disruption at the system scale clearly does not necessarily rely on a classic 'disruptive innovation' at the firm level.

\subsection{Overlooking other routes to disruption: limits of a niche-based view}

A second limitation of Christensen's approach, from a transitions perspective, is the focus on market niches. Christensen's approach provides a neat description of a widely observed phenomenon: lead firms being disrupted by newcomers offering a simpler, cheaper alternative. This focus on the establishment of market niches, and their role in incubating radical novelty, has clear echoes in the multi-level perspective (Geels 2002; Foxon and Pearson 2008).

But focusing on this route to disruption alone would be a mistake: as a lengthy debate in the sustainability transitions literature has noted, there are many pathways to radical transformation. A niche market-based view is only one such path (Genus and Coles 2008; Smith et al. 2005)), and a focus on Christensen's theory overlooks alternative disruptors. Social movements, landscape developments and reconfiguration by incumbents have all been important in past transitions (Geels and Schot 2007). By neglecting these alternative routes to disruption, Christensen clearly limits the applicability of disruptive innovation theory to prospective transitions.

\subsection{Public goods, public policy and low-carbon transitions}

An exclusive focus on market niches as a spur to transitions is particularly limiting in the context of transitions to lower-carbon energy systems. Reducing carbon emissions is a public good, for which no natural markets exist. Without public policies in place to direct it away from high-carbon trajectories, innovation-disruptive or otherwise-should not be expected to generate a low-carbon transition (van den Bergh 2013).

Christensen's theory excludes public policy and the political processes that shape it. But as Meadowcroft has argued, a satisfactory framework for addressing low-carbon transitions must include a role for politics if it is to be a useful guide to policy (Meadowcroft 2009). The coevolutionary interplay between innovation and regulation is critical for understanding how lowcarbon transitions can come about: As Porter and van der Linde argued, environmental regulation 
can induce innovation (Porter and Van der Linde 1995); the less well documented but also important fact is that innovation enables regulation - by bringing down the expected costs of regulation.

\section{Why Christensen's approach remains relevant}

The three limitations set out above make clear that Christensen's theory of disruptive innovation does not provide a framework that can be account for low-carbon transitions. Assertions that a lowcarbon transition requires disruptive innovation should be tempered by the fact that disruptive innovation alone may not be enough.

However, in spite of those limitations Christensen's theory does have relevance for low-carbon transitions, by highlighting important mechanisms that contribute to transitions. In particular, the value in the disruptive innovation idea is that it highlights the tendency for analysts to overlook 'overserved' users or missing markets.

\subsection{Low-end footholds: challenging tacit assumptions about user needs}

Christensen's observation that leading firms are taken by surprise by the strategic importance of over-served users is a reminder for policy analysts and low-carbon innovators to keep an open mind about what consumers will accept, and to ask themselves whether there are portions of the market that are being overserved. The positive message for policy here is the idea of the 'over-served' user. If these users are over-served in terms of energy services, then low-end foothold strategies may enable lowering of total energy service demands.

Where might we find such overserved users? One example might be mobility markets, where the costs associated with vehicle ownership are a significant portion of average household expenditure, ${ }^{1}$ yet most vehicles sit idle for $95 \%$ of the time (Bates and Leibling 2012). Ownership of a typical car provides more power, range and other features than are actually used by most motorists (Transportation Research Board and National Research Council 2015). Little wonder that car-sharing services like Zipcar have been heralded as potentially 'disruptive innovators' (Chase 2016), as have electric bicycles (Ruan et al. 2014). Transport policy is typically based on (often tacit) assumptions about the durability of the socio-technical regime around private car ownership - and Christensen's theory should be a reminder to policymakers about the potential for disruption to that model.

Christensen's approach to disruptive innovation - which focuses on identifying potentially overserved users and thus 'low-end footholds' - can thus be helpful for policymakers and innovators seeking to identify opportunities to disrupt incumbents. The challenge for policymakers is to understand how potentially disruptive change can be directed towards lower-carbon outcomes.

This is also important for energy and integrated assessment modelling frameworks. Such models play an often powerful role in policy processes, providing evidence that is used to frame and inform socio-technical choices (Strachan et al. 2009; McDowall et al. 2014). These tools tend to assume that user needs are relatively constant, and that technologies compete to meet those needs. For

\footnotetext{
${ }^{1}$ In the US, average costs associated directly with vehicle ownership, excluding fuel, are around $10 \%$ of average household total expenditures (ORNL 2016). In the UK, the figure is around 6\% (ONS 2017). Similar data for the EU are available from the EEA (2011)
} 
example, within energy system optimisation model representations of road transport, assumptions are typically made about the minimum acceptable annual average distance, power, and other attributes - all of which are based on current consumer behaviour (McDowall 2014).

Such assumptions preclude the possibility that users are over-served - and a critical review of such models with Christensen's theory in mind might alert us to the risks of assuming that user demand characteristics are stable. Revising the assumptions in such models about acceptable range, acceptable power output, or car sharing could have large influences on the apparent desirability of alternative vehicles. For example, the life-cycle costs of electric vehicles relative to internal combustion vehicles would be greatly improved if higher vehicle usage rates were assumed, since electric vehicles have relatively higher shares of their costs as upfront capital costs rather than perkilometre operational costs.

Assumptions at this level of detail are rarely, if ever, reported by those communicating the results of such models to decision-makers (see e.g. (McDowall et al. 2014)). The result is that models tend to further contribute to conservative expectations about future possibilities, by assuming away the possibility of shifts in user behaviour.

\subsection{New market footholds and rapid market growth}

The idea of 'new market footholds' is potentially more challenging for aspirations to harness disruptive innovation to facilitate a low-carbon transition: new goods and services tend to mean new energy service demands (Christensen's examples of historical 'new market' disruptions include Ford's introduction of the Model T, which dramatically expanded the market for cars, transforming mobility and energy use for transportation).

Where might one expect new markets with relevance for a low-carbon transition to develop? We might focus attention on technological innovation that is enabling new modes of consumption of energy services. The emergence of high energy-density battery technologies has been welcomed as potentially game-changing technology for enabling a low-carbon energy system, by helping to optimise system use of variable renewable energy sources. But this overlooks the possibility that better batteries might be expected to facilitate the emergence of new markets for services requiring portable energy. While policymakers have focused on the potential for batteries and energy storage to enable the more-efficient operation of existing systems and markets, Christensen's theory suggests we should be focusing on the possibility of new markets being enabled: heated clothing ${ }^{2}$, perhaps, or self-driving luggage ${ }^{3}$ - or as yet unimagined energy-consuming goods and services.

Moreover, we should look out for existing products and services that only the wealthiest can currently afford, but which many people would like. To take a perhaps extreme example, consider personal helicopters. They are currently impossibly expensive for most, not least because of the cost of a qualified pilot. But new drone-type electric helicopters are emerging with prices expected to be comparable with high-end sports cars, and without the need for an expert pilot (Williamson 2017).

\footnotetext{
2 Such as Keis https://www.keisapparel.co.uk/

${ }^{3}$ See, for example, the Modobag http://modobag.com/ or the Travelmate: http://travelmaterobotics.com/
} 
These specific examples are almost certainly wrong, as are most technological predictions, but the point is that policymakers should not expect new technologies to only optimise existing systems. Rather, we should expect new entrants to use those technologies to create new markets for new goods and services. It is troubling, from a decarbonisation perspective, that most of these new markets create new energy service demands.

Again, rapid growth in energy service demands are typically excluded from modelling exercises, since forecasts of demand growth are typically based on econometrically-derived relationships between income and energy demand. Such historical relationships may be ill-suited for predicting shifts in energy service demands enabled by a new set of product types (such as personal aviation).

Disruptive innovation theory makes clear that analysts and industry experts are frequently poor at identifying potential sources of new market growth, suggesting that modellers and scenario developers should pay attention to the possibility of new markets for energy services developing.

\section{Conclusion}

Perhaps unsurprisingly, Christensen's pithy phrase has become ubiquitous in discussions of innovation, and it has often been used in a broader sense than his theory describes, as a synonym for any innovation that has a major impact (Examples in the energy sector include (e.g. (Sauter and Watson 2007; Hardman et al. 2013)). Christensen himself has been a fierce critic of attempts to broaden his concept: its value, he argues, lies in its analytic clarity and simplicity. I largely agree - the value of Christensen's theory is that it captures the dynamics of a specific phenomenon. This narrow focus prevents it from being a broad explanatory framework directly applicable to the challenges of decarbonising the global energy system. Rather, Christensen's work is a useful contribution to a wider body of understanding on the mechanisms of stability and change in socio-technical systems, and it needs to be understood as one mechanism among many.

\section{References}

Bates, J. and D. Leibling. 2012. Spaced out: perspectives on parking policy. RAC Foundation, London. Bower, J. L. and C. M. Christensen. 1995. Disruptive Technologies - Catching the Wave. Harvard Business Review 73(1): 43-53.

Chase, R. 2016. We need to expand the definition of disruptive innovation. Harvard Business Review. Christensen, C. and M. Raynor. 2003. The innovator's solution: Creating and sustaining successful growth: Harvard Business Review Press.

Christensen, C., M. Raynor, and R. McDonald. 2015. What is disruptive innovation? Harvard Business Review December: 44-53.

EEA. 2011. Expenditure on personal mobility, Prod-ID: IND-174-en, or TERM 024. European Environment Agency, Copenhagen. Available online: https://www.eea.europa.eu/data-andmaps/indicators/expenditure-on-personal-mobility-2/assessment [accessed 11th October 2017]. 
Foxon, T. and P. Pearson. 2008. Overcoming barriers to innovation and diffusion of cleaner technologies: some features of a sustainable innovation policy regime. Journal of Cleaner Production 16(1): S148-S161.

Geels, F. W. 2002. Technological transitions as evolutionary reconfiguration processes: a multi-level perspective and a case-study. Research Policy 31(8-9): 1257-1274.

Geels, F. W. and J. Schot. 2007. Typology of sociotechnical transition pathways. Research Policy 36(3): 399-417.

Genus, A. and A. M. Coles. 2008. Rethinking the multi-level perspective of technological transitions. Research Policy 37(9): 1436-1445.

Grubler, A. 2012. Energy transitions research: Insights and cautionary tales. Energy Policy 50(0): 816.

Hardman, S., R. Steinberger-Wilckens, and D. van der Horst. 2013. Disruptive innovations: The case for hydrogen fuel cells and battery electric vehicles. International Journal of Hydrogen Energy 38(35): 15438-15451.

McDowall, W. 2014. Exploring possible transition pathways for hydrogen energy: A hybrid approach using socio-technical scenarios and energy system modelling. Futures 63(0): 1-14.

McDowall, W., P. Ekins, S. Radošević, and L.-y. Zhang. 2013. The development of wind power in China, Europe and the USA: how have policies and innovation system activities co-evolved? Technology Analysis \& Strategic Management 25(2): 163-185.

McDowall, W., E. Trutnevyte, J. Tomei, and I. Keppo. 2014. Reflecting on scenarios. UKERC Energy Systems Theme Working Paper no. UKERC/WP/ES/2014/002: UKERC.

Meadowcroft, J. 2009. What about the politics? Sustainable development, transition management, and long term energy transitions. Policy Sciences 42(4): 323.

ONS. 2017. Components of Household Expenditure, Table A1. Office of National Statistics, Newport. Available online

https://www.ons.gov.uk/peoplepopulationandcommunity/personalandhouseholdfinances/e xpenditure/datasets/componentsofhouseholdexpenditureuktablea1 [accessed 11th October 2017].

ORNL. 2016. Chapter 8, Transportation Energy Data Book. Oak Ridge National Laboratory, Knoxville.

Porter, M. E. and C. Van der Linde. 1995. Toward a new conception of the environmentcompetitiveness relationship. The Journal of Economic Perspectives 9(4): 97-118.

Ruan, Y., C. C. Hang, and Y. M. Wang. 2014. Government' s role in disruptive innovation and industry emergence: The case of the electric bike in China. Technovation 34(12): 785-796.

Sauter, R. and J. Watson. 2007. Micro-generation: a disruptive innovation for the UK energy system? People centred eco-design: consumer adoption of low and zero carbon products and systems: 110.

Smith, A., A. Stirling, and F. Berkhout. 2005. The governance of sustainable socio-technical transitions. Research Policy 34(10): 1491-1510.

Strachan, N., S. Pye, and R. Kannan. 2009. The iterative contribution and relevance of modelling to UK energy policy. Energy Policy 37(3): 850-860.

The Economist. 2017. Wind and solar power are disrupting energy systems. February 25th. The Economist, London. Available online: https://www.economist.com/news/leaders/21717371thats-no-reason-governments-stop-supporting-them-wind-and-solar-power-are-disrupting (Accessed 18th September 2017).

Transportation Research Board and National Research Council. 2015. Overcoming Barriers to Deployment of Plug-in Electric Vehicles. Washington, DC: The National Academies Press.

Unruh, G. C. 2000. Understanding carbon lock-in. Energy Policy 28(12): 817-830.

van den Bergh, J. C. J. M. 2013. Environmental and climate innovation: Limitations, policies and prices. Technological forecasting and social change 80(1): 11-23.

Williamson, M. 2017. SureFly personal helicopters using drone simplicity to disrupt aviation industry. Engineering and Technology, Friday 4th July, section. 
